
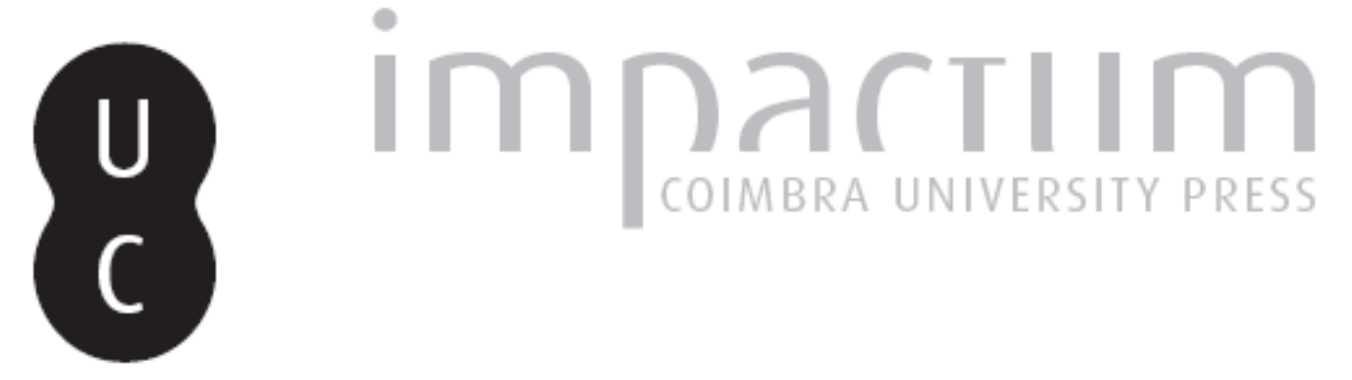

\title{
[Recensão a] Immanuel Wallerstein - The Modern World-System - Capitalist agriculture and the origins of the european world-economy in the sixteenth century
}

Autor(es): $\quad$ Pereira, José Esteves

Publicado por: Imprensa da Universidade de Coimbra

URL persistente:

URI:http://hdl.handle.net/10316.2/43981

DOI:

DOI:https://doi.org/10.14195/2183-8925_1_13; DOI:0870-0958

Accessed : $\quad$ 26-Apr-2023 12:06:52

A navegação consulta e descarregamento dos títulos inseridos nas Bibliotecas Digitais UC Digitalis, UC Pombalina e UC Impactum, pressupõem a aceitação plena e sem reservas dos Termos e Condições de Uso destas Bibliotecas Digitais, disponíveis em https://digitalis.uc.pt/pt-pt/termos.

Conforme exposto nos referidos Termos e Condições de Uso, o descarregamento de títulos de acesso restrito requer uma licença válida de autorização devendo o utilizador aceder ao(s) documento(s) a partir de um endereço de IP da instituição detentora da supramencionada licença.

Ao utilizador é apenas permitido o descarregamento para uso pessoal, pelo que o emprego do(s) título(s) descarregado(s) para outro fim, designadamente comercial, carece de autorização do respetivo autor ou editor da obra.

Na medida em que todas as obras da UC Digitalis se encontram protegidas pelo Código do Direito de Autor e Direitos Conexos e demais legislação aplicável, toda a cópia, parcial ou total, deste documento, nos casos em que é legalmente admitida, deverá conter ou fazer-se acompanhar por este aviso.

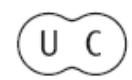




$$
\text { INSTITUTO DE HISTÓRIA E TEORIA DAS IDEIAS }
$$

\title{
REVISTA DE HISTÓRIA $D A S$ IDEIAS
}

\author{
VOL. I
}

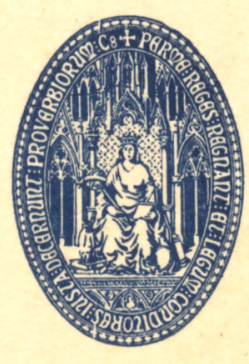

UNIVERSIDADE DE COIMBRA 


\section{I mmanuel Wallerstein - The Modern World-System - Capitalist agriculture and the origins of the european world-economy in the sixteenth century, New York, Academic Press, 1974, XIV + 410 pp.}

O presente texto, considerado por Fernand Braudel como a mais subtil obra de história analítica publicada nos últimos dez anos, merece atenção especial. Como Braudel referiu ainda, o problema de uma economia mundial não era desconhecida dos historiadores, mas Wallerstein construiu um enquadramento revolucionário sobre o assunto. Permitir-nos-íamos dizer que, após a exemplar análise de Pierre Dockès sobre a conceptualização dos espaços económicos europeus do séc. XVII e seu estudo, esta obra, ainda pouco conhecida entre nós, mereceu o vaticínio de Andre Gunder Frank de que se tornaria clássica imediatamente em seguida à sua publicação.

A construção de um sistema mundial (World-system), como campo de estudo de um «cosmos» experimental histórico, não exclui, para Wallerstein, uma referência epocal bem definida, mesmo que denunciadora de uma menor preocupação cronológica que, aliás, o propósito fundamental da sua tese não exige. E assim este primeiro volume, integrado na série de estudos sobre descontinuidade social, supervisados editorialmente por Charles Tilly, da Universidade do Michigan, e Edward Shorter, da Universidade de Toronto, comportará o seguinte desenvolvimento: 1. A época de 1450-1640, abordada no volume que estamos a tratar; 2 . a consolidação do sitema mundial; 3. a conversão da economia mundial numa empresa global, tornada possível pela transformação tecnológica do industrialismo moderno (1815-1917); 4. a consolidação da economia capitalista mundial, de 1917 ao presente, e em particular as tensões «revolucionárias» que esta consolidação provocou.

Wallerstein, ao apresentar o conceito de sistema mundial, entende-o como superador de coordenadas de estudo que se têm revelado inoperacionais para a compreensão de estruturas que ainda se reflectem na nossa auto-consciência histórica.

Neste primeiro volume, teremos de atender, também, para lá dos temas analisados, a considerações metodológicas e epistemológicas preliminares, para melhor perceber a «tese» do autor.

Wallerstein desenvolve o seu estudo de molde a que a conclusão seja a possível resposta à situação de perplexidade e de alienação no processo histórico. Por tal facto, é a sua obra exercício permanente de pergunta a um tempo histórico e às opções teóricas que o encobrem. Em face da questão de saber se toda a história é história de luta de classes, ocorre a dúvida de que sejam as "classes» as únicas unidades operatórias nas «arenas» políticas e sociais. Não é estranha à reflexão de tal dúvida a experiência africana do autor, mormente no período gestatório das independências, e as formações sociais em que os agentes emancipadores evoluiram.

Questão pertinente é ainda, a do consenso de valores dentro de cada sociedade e a equivalência prática às ideologias. Tema que me parece relevante, quer em visão contemporânea, quer na perspectiva diacrónica desenvolvida por Wallerstein, seja para o espaço de "colonialismo» africano, seja para o espaço europeu noutra 
dimensão cronológica, seja para os condicionalismos determinantes da América Latina ou mesmo da América do Norte no século XVIII.

$O$ autor teria assim que desenvolver, no seu mundo de análises, referências e graus que, partindo de núcleos dominantes, se expressam em zonas periféricas de absorção, ou em "arenas», totalmente ou em parte, estranhas ao processo. Mas como se pode constatar, a relação de factores, se desmistificada de capas teóricas e ideológicas, enquadra-se também para além de puras demarcações económicas ou de criações problemáticas, como seja a de «unidade nacional». Daí que uma unidade nacional só possa contar como elemento operacional integrado na estrutura ampla do sistema mundial de relacionamento social. Será no posicionamento de tais elementos que se poderá perguntar, com mais amplitude, se, por exemplo, é a industrialização um ponto de viragem ou a consequência de algum ponto de viragem político? Os estádios de desenvolvimento são unilineares ou admitem recuos? Em que medida, em que contexto mundial, semelhanças estruturais se diferenciam historicamente? E assim por diante.

É óbvio que tal trabalho só era possível a um certo nível de abstracção. $\mathrm{O}$ autor adverte-nos disso. Verifica-se o primado da conceptualização sobre quantificação, por exemplo. O grau de quantificação reflecte, tão-só, o máximo de precisão possível para dados problemas e dado tempo pontual. $\mathrm{O}$ mesmo pode acontecer na determinação cronológica de dadas séries.

A última prevenção que o autor faz tem a ver com a sua concepção de história. Opondo-se à máxima oitocentista da história exacta, coloca-se na posição de que o passado só pode ser narrado como é, não como era. Daí a superação justificativa de um recontar do passado como acto social presente feito por homens do presente e afectando o sistema social do presente: "A verdade muda porque a sociedade muda. Em dado tempo, nada é sucessivo; tudo é contemporâneo, mesmo aquilo que é passado».

Sobre o desenvolvimento temático do volume I, importará referir o estudo da génese medieval de uma "economia mundial» restritiva do económico, em proveito, todavia, de condicionantes políticos e culturais que tinham por cenário a estrutura do «Império». No desenvolvimento da extensa obra, saliente-se ainda o problema da nova divisão do trabalho emergente na época de Quinhentos, o estatismo e a monarquia absoluta, a translacção do eixo comercial de Sevilha para Amesterdão, a correlativa formação de Estados nucleares em que nos aparecem novas formações sociais e novas relações económico-comerciais geradoras do que nos tempos modernos se estatui no amplo conceito de comércio mundial e suas influências de índole geopolítica.

O trabalho, no que respeita ao primeiro volume, o único publicado por enquanto, conclui com uma análise sobre a dicotomia polémica de Periferia e Arena Externa (Periphery versus External Arena, pp. 301-357).

Anotaremos, por dizer especial respeito à esfera de actuação portuguesa no sistema mundial do século XVI, a existência de uma arena externa em que nos situamos, no Índico.

As relações comerciais e económicas intra-asiáticas, o seu modo de produção, de forma nenhuma foram afectadas, no período ibérico da expansão. A planificação militar e comercial portuguesa, de tipo costeiro, explicará até o nosso maior sucesso em relação à Espanha, nestas paragens. De qualquer modo, o envolvimento 
ibérico na Ásia não permitiu qualquer política de intervenção ou permanência efectiva no contexto intra-asiático. A expansão portuguesa no Oriente tem de ser estudada ao nível de relações sócio-económicas, de entreposto.

A situação é diferente, todavia, quando deparamos com a política dos dois países ibéricos nas Américas. Aqui, ao contrário de uma "arena» externa de actuação, estamos perante uma acção directa do estado nuclear. Por consequência, o espaço brasileiro tornou-se periférico em relação a Portugal e susceptível de um enquadramento político e social. Não existia na América espanhola ou portuguesa uma formação política, social ou económica concorrencial com os países descobridores na organização interna do espaço («Americas became the periphery of the european world-economy in the sixteenth century while Asia remained an external arena», p. 336). A colonização americana será, pois, uma opção europeia de menores custos económicos sociais, e políticos. E será, também, a consequência lógica da dificuldade de penetrar na "arena" asiática. Este espaço ficará guardado para novo intento expansionista europeu, no período mercantilista do século XVII.

Wallerstein, ao reflectir sobre estes problemas, extrai um «quantum» expansionista: um sistema económico (social e político) dado expande-se até atingir o ponto em que as perdas são maiores que os ganhos. Parece-nos reflexão interessante sobre o evoluir expansionista do capitalismo em época posterior à estudada até agora pelo autor.

Mas voltando ainda à arena asiática, em breve a ser subalternizada pela exploração americana, Wallerstein sublinhará também a mudança estrutural portuguesa ocorrida em 1560, com a bancarrota nacional, sucedâneo de idêntico fenómeno, em 1557, em Espanha e França. Aí aparecerá a Europa do Norte, como expressão nuclear de actuação.

O autor não estudou, neste volume, as condições internas da primitiva ascensão holandesa e inglesa, que a partir dos princípios do século XVI se fará sentir. Voltado para a dinâmica de um sistema mundial que, abandonando o capitalismo agrário, arranca para uma economia de expansão, situa-se, e com êxito, em quadrantes de maior significado analítico, isto é, no fenómeno da duplicação de lucros. Este fenómeno consistia no "Asian contract» e no "European contract». Os produtos produziam um ganho no circuito comercial, da Ásia para Lisboa (ou Veneza, e mais tarde Amesterdão) e na revenda, em ponta, no sector de comercialização e consumo, no Norte da Europa.

Esta obra, bem documentada, reveste-se de urgente importância sobre as condições em que o nosso percurso expansionista se situa. A actualidade metodológica não é menor, enquanto correctivo de opções de história económica e social distorcidas por meras catalogações quantitativas e inferências displicentes ou cobertas por esquemas ideológicos racionalistas, senão "escolásticos», e em todo o caso deformantes. 